\title{
Metabolic syndrome: Did the creator kill the creature?
}

Síndrome metabólica: O criador afinal matou a criatura?

Éder C. Quintão'

$\mathrm{R}^{\mathrm{c}}$ ecently, a review was published by G. M. Reaven entitled "The metabolic syndrome: time to get off the merry-go-round" (1). I chose a different title for the subject, which I felt was more appropriate, for the following reasons. I relished Reaven's article for its clarity and depth, and I wish to congratulate him for his courageous text, which demolishes conventional ideas by means of well-written technical arguments. The text came as a delightful surprise, considering that the whole concept of metabolic syndrome had been sponsored by him for more than 20 years (2), and had received the support of a multitude of equally wise fellow researchers, including some Brazilian ones.

The arguments that G. M. Reaven presents are a timely reward to those, such as I, who have never shared his beliefs. As an endocrinologist, I have neither measured waist/ hip circumferences, nor given any attention to what I have considered a capricious and useless need to tag a patient as bearing a metabolic syndrome to take actions to prevent that patient from developing or aggravating his/her cardiovascular disease. We have seen, over the years, that metabolic syndrome is a list of parameters that is continuously being modified, and varies among different countries and societies. Furthermore, its prestige and usefulness run parallel with the support given to it by the number of attendees and the importance of international meetings, impact indexes of the international periodicals that have published articles on it, and the economic importance of the countries where it was initially defined. Finally, I should mention that, as a naïve and gullible person, I have always trusted that the pharmaceutical companies never meddled in this field!

To make a long story short, metabolic syndrome was initially coined as Syndrome X (2). After many efforts, Syndrome X reached maturity and took on the new name "metabolic syndrome", although I never failed to deem it as a premature newborn. Although attired in new clothes, the soul of this syndrome - that is, its genetic evidence - has yet to be found. Indeed, before exposing the highlights of Reaven's review and conclusions, I should add that I have always felt uncomfortable with the fact that metabolic syndrome has remained immune to the need for genetic definitions, during a period in which gene exploration has produced remarkable explanations for so many metabolic disorders.

Although I apologize for quoting directly from much of Reaven's text, while sparing the readers from analyzing all his pointed arguments, I will briefly highlight his major conclusions: 1) according to the latest WHO report, "metabolic syndrome should not be a clinical diagnosis" and "has limited practical utility as a diagnostic or management tool"; 2 ) "there are metabolically healthy obese subjects ( $51 \%$ of overweight individuals), metabolically abnormal obese individuals (32\%), and $24 \%$ normal weight individuals who are metabolically abnormal"; "it seems reasonable to simply classify individuals normal weight or obese as a function of their metabolic risk"; 3 ) "the ability of body mass index to predict type $2 \mathrm{DM}$ or cardiovascular disease is also comparable to that achieved with measurements of the waist circumference" (incidentally, one of the mutable tenets of the definition); 4) when matched with waist circumference, $\mathrm{BMI}$ also has an independent effect on the steady state plasma glucose value (SSPG);
1 Professor Emérito de

Endocrinologia, Faculdade de Medicina da Universidade de São Paulo (FMUSP), membro da Academia Brasileira de Ciências, São Paulo, SP, Brasil

Correspondence to: Éder C. Quintão equintao@terra.com.br

Received on Feb/22/2011 Accepted on Jun/3/2011 
"there are very few normal-weight individuals in the abnormal waist circumference group"; 5) in discussing a report (3) claiming that "BMI and particularly waist circumference were both strongly linked to cardiovascular disease and especially to diabetes", G. M. Reaven correctly disagrees by concluding that BMI and waist circumference links to these pathologies do not differ substantially; 6) he asks next, "is there any clinical benefit in differentiating patients with Type $2 \mathrm{DM}$ on the basis of whether they also qualify for the metabolic syndrome: type 2DM with metabolic syndrome versus type 2 DM without metabolic syndrome?"; His answer was "that all cardiovascular disease risk factors should be individually and aggressively treated"; 7) Reaven confesses "the ability of the metabolic syndrome to identify individuals at risk for type $2 \mathrm{DM}$ and/or cardiovascular disease is no better than its competent parts", namely, each parameter utilized to define metabolic syndrome; 8) "none of this information (on the metabolic syndrome) has provided new pathophysiological insight, nor does it support the clinical utility of the metabolic syndrome as a diagnostic category"; 9) "if a patient meets the diagnosis criteria for diabetes mellitus type 2 or essential hypertension, does knowing whether or not they also meet the criteria for the metabolic syndrome going to affect the treatment plan?"; He concludes against this possibility by adding the question "is there any reason why the metabolic syndrome category should not be given its well-deserved rest?"; 10) "there is no evidence that a diagnosis of the metabolic syndrome improves our ability to identify individuals at increased risk of type 2 DM or cardiovascular disease"; and 11) "the Framingham Risk Study provides a more useful way to identify individuals at risk for cardiovascular disease than the metabolic syndrome".

To all of these wise arguments, I add that, in my practice, I have cared about fasting blood glucose, triglycerides, HDL, and arterial blood pressure and I am aware that each one of them may be under some genetic control or environmental influence, and that cardiovascular protection can be effectively reached despite not taking into account the patient's waist circumference. How misguided were those who considered that by adding the latter parameter to the other ones, which are controlled by multiple genes, a single gene might explain the whole syndrome!

Reaven's conclusions redeem the sins of many, such as I, who have treated their patients solely on the basis of canonical criteria (like those of the Framingham and PROCAM metrics, as well as a few other metrics), which include conventional, major risk factors for cardiovascular disease, such as age, gender, hypertension, smoking, lipid values, diabetes, and family history, and who have cared about body mass index only when it was connected with one of the aforementioned major risk factors. I dare to further argue that I belong to that category of skeptics who seldom bother about homocysteine, C reactive protein, and minor cardiovascular risk factors when dealing with patients under my care. I am happy to confess that I have neither told medical residents that I had to label someone as having "the syndrome", nor that this was necessary to prevent him or her from developing new, or aggravating his or her preexisting cardiovascular disease.

I recall that some of my peers at major international meetings used to hotly discuss metabolic syndrome when they attended important conferences on the topic. But in private, they candidly confessed that they cared far more about measuring the ankle/brachial blood pressure index (a regrettably neglected procedure in our country!) than they bothered about labeling the patient in the metabolic syndrome category. Although I risk being impolite, I disclose here the answer I got from G. M. Reaven, many years ago, at an international meeting; if I recall correctly, it was something like "you do not understand what I am presenting here". I am now quite glad that he has finally understood what he and others had been writing about for so many years.

Before drawing the premature conclusion that science indeed progresses through the waste of money, and although Reaven's conclusions are likely to be devastating to those who for years have been enthusiastic about the usefulness of the metabolic syndrome concept, we should not be that pessimistic. While searching for its etiology, much has been learned about the role of adipose tissue in inflammation and physiology, the mechanisms of insulin resistance, adipose tissue as an endocrine organ, and certainly much more. However, I have to say that I felt that metabolic syndrome had already passed its time many years ago. I extend my condolences and sympathies for the tears of the many metabolic syndrome widows and destitute orphans who have been left behind.

Disclosure: no potential conflict of interest relevant to this article was reported.

\section{REFERENCES}

1. Reaven GM. The metabolic syndrome: time to get off the merry-go-round? J Intern Med. 2010;269(2):127-36.

2. Reaven GM. Role of insulin resistance in human disease (syndrome X): an expanded definition. Annu Rev Med. 1993;44:121-31.

3. Balkau B, Deanfield JE, Després JP, Bassand JP, Fox KA, Smith $\mathrm{SC} \mathrm{Jr}$, et al. International Day for the Evaluation of Abdominal Obesity (IDEA): a study of waist circumference, cardiovascular disease, and diabetes mellitus in 168,000 primary care patients in 63 countries. Circulation. 2007;116(17):1942-51. 